\title{
Establishing a Canadian Registry of Patients with Amyotrophic Lateral Sclerosis
}

\author{
L. Korngut, A. Genge, M. Johnston, T. Benstead, P. Bourque, H. Briemberg, \\ A. Casey, M. D'Amour, N. Dupré, D. Figlewicz, W. Hader, W. Johnston, S. Kalra, \\ M. Melanson, C. O'Connell, G. Rouleau, C. Shoesmith, J. Wee, L. Zinman
}

\begin{abstract}
Background: Amyotrophic lateral sclerosis (ALS) is a devastating cause of progressive weakness, respiratory failure and death. To date there is no effective therapy to meaningfully extend survival but continuously emerging targets and putative treatments are studied in clinical trials. Canadian epidemiological data on ALS is scarce and the socioeconomic impact of ALS on Canadian society is unclear. The Canadian Neuromuscular Disease Registry (CNDR) is a national clinic-based registry of patients with neuromuscular diseases with the goal of facilitating the design and execution of clinical research. Methods: We conducted a national stakeholder survey to assess interest for a Canadian ALS registry and an assessment of expected case ascertainment. A dataset derivation meeting was held to establish the registry medical dataset. Results: We report the results of the national stakeholder survey, case ascertainment assessment, and the derived dataset that have resulted in the current implementation of a Canadian registry of patients with ALS. Conclusions: The development of this long sought-after resource is a significant step forward for the Canadian ALS patient and research communities that will result in more efficient clinical trial recruitment and advancements in our understanding of ALS in Canada.
\end{abstract}

RÉSUMÉ: Création d'un registre canadien de patients atteints de la sclérose latérale amyotrophique. Contexte : La sclérose latérale amyotrophique (SLA) est une cause dévastatrice de faiblesse progressive, d'insuffisance respiratoire et de décès. À ce jour, il n'existe pas de traitement efficace pour prolonger significativement la survie des patients qui en sont atteints. De nouvelles cibles thérapeutiques et de nouveaux traitements font actuellement l'objet d'essais cliniques. Il existe peu de données épidémiologiques canadiennes sur la SLA et son impact socioéconomique sur la société canadienne est mal connu. Le Canadian Neuromuscular Disease Registry (CNDR) est un registre national, basé sur la présentation clinique de patients atteints de maladies neuromusculaires, dont le but est de faciliter la conception et la réalisation de la recherche clinique. Méthode : Nous avons effectué une enquête nationale auprès des parties concernées pour évaluer l'intérêt pour la création d'un registre canadien de la SLA et le nombre de cas attendus. Une rencontre a eu lieu dans le but d'élaborer un fichier de données afin de définir le fichier médical du registre. Résultats : Nous rapportons les résultats de l'enquête nationale effectuée auprès des parties concernées, comment les cas seront évalués et quelles données seront recueillies. Ces démarches ont servi de base à l'établissement d'un registre canadien de patients atteints de la SLA. Conclusions : Le développement de cette ressource attendue depuis longtemps est un pas en avant important pour les patients canadiens atteints de la SLA et pour la communauté scientifique et facilitera le recrutement de patients pour les essais cliniques et l'avancement des connaissances dans le domaine de la SLA au Canada.

Can J Neurol Sci. 2013; 40: 29-35

Amyotrophic lateral sclerosis (ALS) is a relatively common cause of progressive weakness, respiratory failure and death. Although ALS has a low incidence of 1-2 per 100,000/year the cumulative lifetime risk has been shown to be as high as 1 in $338^{1}$. There is no effective therapy to meaningfully extend survival but continued elucidation of the pathophysiology is resulting in continuously emerging targets and treatments for study in clinical trials ${ }^{2}$. Unfortunately Canadian epidemiological data on ALS is scarce and the socioeconomic impact of ALS on Canadian society remains unclear.

While the majority of clinical trials in ALS examine therapeutic efficacy in populations of predominantly sporadic ALS subjects, a growing number of trials are focusing on subjects with genotyped familial ALS (FALS). The principal barrier limiting the number of trials being conducted in the general ALS population and in sub-groups is recruitment,

From the Department of Clinical Neurosciences (LK, MJ), Hotchkiss Brain Institute, University of Calgary, Calgary; Division of Neurology (WJ, SK), University of Alberta,

Edmonton, Alberta; ALS Program (AG), Montreal Neurological Institute and Hospital; Department of Neurology (MD), Hopital Notre-Dame, Centre Hospitalier Universitaire de

Montreal; Universite de Montreal and Research Centre, Hospitalier Universitaire Sainte-Justine (GR), Montreal; Department of Neurological Scnience (ND) CHA-Enfant-Jésus,

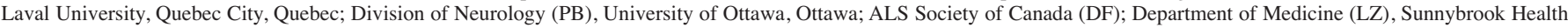

Sciences Centre, Toronto, Ontario; Stan Cassidy Centre for Rehabilitation (CO), Fredricton, New Brunswick; Division of Neurology (TB), Dalhousie University, Halifax, Nova

Scotia; Division of Neurology (HB), University of British Columbia, Vancouver, British Columbia; Section of Physical Medicine and Rehabilitation (AC), University of Manitoba,

Winnipeg, Manitoba; Department of Physical Medicine and Rehabilitation (WH), University of Saskatchewan, Saskatoon, Saskatchewan, Canada.

Received June 26, 2012. Final Revisions Submitted July 5, 2012.

Correspondence to: Lawrence Korngut, Clinical Neurosciences, South Health Campus, 4448 Front Street SE, Calgary, Alberta, T3M 1M4, Canada. Email: korngut@gmail.com. 
specifically, a lack of readily accessible patients meeting enrollment criteria, necessitating collaboration across countries and continents to secure sufficient numbers of eligible subjects.

Consortia and infrastructure to facilitate collaborative research into risk factors, genetics, biomarkers, and execution of clinical trials are being developed around the world ${ }^{3,4}$. Patient registries have been identified as a vital component of the tools required for new therapy development ${ }^{5-7}$. Patient registries provide real world data that is highly generalizable and has been used to expand indications for medical procedures beyond that of those justified by pivotal clinical trials ${ }^{8}$.

The Northern Ireland motor neuron disease (MND) patient register has demonstrated near complete ascertainment using capture-recapture methodology allowing the registry to provide estimates of incidence, prevalence and geographic distribution ${ }^{9}$. The utility of such information in Canada is evident given the considerable health care resources required by ALS patients across vast geographic regions and the difficulty in planning clinical trials that should include a representative sample of the Canadian ALS patient population. Existing ALS patient registries have also refined epidemiological estimates of FALS patients in various regions outside of Canada allowing improved feasibility and impact assessments for prospective FALS clinical trials and studies ${ }^{10}$.

Patient registries employ a spectrum of models to register subjects and collect medical data ranging from online selfregistration (often cross referencing with administrative data) to clinic-based registration completed by the attending physician. Importantly, the model employed should meet the needs of the
Table 1: Feasibility survey dataset item rankings

\begin{tabular}{l|c}
\multicolumn{1}{c|}{ Potential Dataset Item } & Average Rank \\
\hline $\begin{array}{l}\text { Clinical trial recruitment (common } \\
\text { inclusion/exclusion criteria) }\end{array}$ & 2.7 \\
\hline $\begin{array}{l}\text { Clinical features (regions of involvement, } \\
\text { ALS subtype etc). }\end{array}$ & 3.2 \\
\hline Genetics & 3.8 \\
\hline $\begin{array}{l}\text { Past exposures/possible risk factors (e.g. } \\
\text { environmental, dietary, lifestyle, } \\
\text { occupational, military service etc) }\end{array}$ & 4.4 \\
\hline $\begin{array}{l}\text { Details of interventions (respiratory, PEG, } \\
\text { etc). }\end{array}$ & 4.6 \\
\hline Medications & 5.5 \\
\hline $\begin{array}{l}\text { Associated symptoms (e.g. cramps, pain, } \\
\text { excessive secretions, pseudobulbar affect } \\
\text { etc) }\end{array}$ & 5.8 \\
\hline $\begin{array}{l}\text { Local tissue inventory (information on } \\
\text { what samples have been collected and } \\
\text { where) }\end{array}$ & 6.2 \\
\hline Co-morbidities & 6.9 \\
\hline
\end{tabular}

specific patient registry and the function that the registry is aiming to serve.

Although limited epidemiological data on ALS in Canada exists, data on geographic distribution, genetics, potential risk factor exposures, multidisciplinary clinic use, health care

Table 2: ALS case ascertainment in proposed clinics by province

\begin{tabular}{|c|c|c|c|c|c|}
\hline PROVINCE & $\begin{array}{l}\text { POPULATION } \\
25 \text { \& OVER }\end{array}$ & $\begin{array}{l}\text { EXPECTED } \\
\text { ALS CASES }\end{array}$ & $\begin{array}{l}\text { REGION BY } \\
\text { CLINIC }\end{array}$ & $\begin{array}{c}\text { ACTIVE } \\
\text { ALS } \\
\text { CLINIC } \\
\text { CASES } \\
\end{array}$ & $\begin{array}{c}\text { EXPECTED } \\
\text { MAXIMUM } \\
\text { ASCERTAINMENT }\end{array}$ \\
\hline \multirow[t]{2}{*}{ Alberta } & \multirow[t]{2}{*}{$2,562,356$} & \multirow[t]{2}{*}{156} & $\begin{array}{l}\text { Calgary } \\
\text { Edmonton }\end{array}$ & $\begin{array}{l}89 \\
90\end{array}$ & \multirow[t]{2}{*}{$115 \%$} \\
\hline & & & Alberta & 179 & \\
\hline British Columbia & $3,279,358$ & 199 & Vancouver & 284 & $143 \%$ \\
\hline Manitoba & 835,445 & 51 & Winnipeg & 59 & $116 \%$ \\
\hline New Brunswick & 547,257 & 33 & Fredericton & 60 & $182 \%$ \\
\hline Nova Scotia & 682,828 & 41 & Halifax & 39 & $95 \%$ \\
\hline \multirow{4}{*}{ Ontario } & \multirow{4}{*}{$9,343,718$} & \multirow{4}{*}{567} & Kingston & 27 & \multirow{4}{*}{$108 \%$} \\
\hline & & & London & 132 & \\
\hline & & & $\begin{array}{c}\text { Sunnybrook } \\
\text { Ottawa }\end{array}$ & $\begin{array}{c}380 \\
72 \\
\end{array}$ & \\
\hline & & & Ontario & 611 & \\
\hline \multirow{4}{*}{ Quebec } & \multirow{4}{*}{$5,740,083$} & \multirow{4}{*}{348} & Montreal - CHUM & 142 & \multirow{4}{*}{$147 \%$} \\
\hline & & & Montreal - MNI & 336 & \\
\hline & & & CHA-Enfant-Jésus & 35 & \\
\hline & & & Quebec & 513 & \\
\hline Saskatchewan & 704,695 & 43 & Saskatoon & 18 & $42 \%$ \\
\hline TOTAL & $23,695,740$ & 1,438 & & 1,763 & $123 \%$ \\
\hline
\end{tabular}

**Population statistics are based on CANSIM Table 051-0001 July 1, 2011.** Prevalence estimates calculated on point prevalence at $6.07 / 100,000$. 
Table 3: Classification of Potential Dataset Items

\begin{tabular}{l|l}
\hline \multicolumn{1}{c|}{ Potential Dataset Item } & \multicolumn{1}{c}{ DATA CATEGORY } \\
\hline $\begin{array}{l}\text { Associated symptoms (e.g. cramps, } \\
\text { pain, excessive secretions, } \\
\text { pseudobulbar affect etc) }\end{array}$ & Highly Encouraged \\
\hline $\begin{array}{l}\text { Clinical features (regions of } \\
\text { involvement, ALS subtype etc). }\end{array}$ & Mandatory \\
\hline $\begin{array}{l}\text { Clinical trial recruitment (common } \\
\text { inclusion/exclusion criteria) }\end{array}$ & Mandatory \\
\hline Co-morbidities & Highly Encouraged \\
\hline $\begin{array}{l}\text { Details of interventions } \\
\text { (respiratory, PEG, etc). }\end{array}$ & Highly Encouraged \\
\hline $\begin{array}{l}\text { Genetics } \\
\text { Local tissue inventory (information } \\
\text { on what samples have been } \\
\text { collected and where, a central } \\
\text { biobank is beyond scope at this } \\
\text { time) }\end{array}$ & Highly Encouraged \\
\hline $\begin{array}{l}\text { Medications } \\
\text { Past exposures/possible risk factors } \\
\text { (e.g. environmental, dietary, } \\
\text { lifestyle, occupational, military } \\
\text { service etc) }\end{array}$ & Highly Encouraged \\
\hline
\end{tabular}

utilization and socioeconomic impact remain unavailable. Despite great strides in collaboration by the Canadian ALS Network (CALS) barriers to efficient international level clinical trial planning and recruitment remain due to lack of information technology infrastructure to facilitate study-eligible patient statistics, including geographic distribution relative to study site locations, and a notification system for potentially eligible patients.

The Canadian Neuromuscular Disease Registry (CNDR) is a national clinic-based registry of patients with neuromuscular diseases with the goal of facilitating design and execution of clinical research. The CNDR currently collects detailed medical information on patients with Duchenne and myotonic muscular

Table 4: Additional dataset items scoring matrix

\begin{tabular}{c|l}
\hline SCORE & \multicolumn{1}{c}{ DESCRIPTION } \\
\hline $\mathbf{5}$ & Mandatory item with national relevance \\
\hline $\mathbf{4}$ & Highly encouraged item with national relevance \\
\hline $\mathbf{3}$ & $\begin{array}{l}\text { Highly encouraged item with personal research } \\
\text { relevance }\end{array}$ \\
\hline $\mathbf{2}$ & Item has low necessity but is of interest \\
\hline $\mathbf{1}$ & $\begin{array}{l}\text { Item is not of interest and/or has no national } \\
\text { relevance }\end{array}$ \\
\hline
\end{tabular}

dystrophies and consists of affiliated regional co-investigators and their respective neuromuscular clinics serving as clinical data collection centres. The CNDR is administered centrally through the national office providing logistical and administrative support. Data is entered using an internet portal to transmit data securely from clinical sites to a centralized server. Following extensive discussion between patients, groups providing clinical or support services, clinicians and researchers and through the partnering of the CNDR, CALS and the ALS Society of Canada it was decided to proceed with the creation of an ALS registry in Canada through the addition of detailed ALS medical information collection capabilities to the existing CNDR database.

\section{Materials \& Methods}

Feasibility study. Between November 10 and December 3, 2010 an online survey was undertaken to assess the feasibility of

Table 5: Additional items ranking and classification

\begin{tabular}{|c|c|c|}
\hline ITEM & $\begin{array}{l}\text { TOTAL } \\
\text { SCORE }\end{array}$ & RANK \\
\hline \multicolumn{3}{|l|}{ Demographic Items } \\
\hline Date of symptom onset & 60 & Mandatory \\
\hline Location of symptom onset & 58 & Mandatory \\
\hline Date of Death & 52 & Mandatory \\
\hline Location of Death & 45 & Mandatory \\
\hline $\begin{array}{l}\text { Community type (e.g. rural, } \\
\text { urban) }\end{array}$ & 42 & Highly Encouraged \\
\hline Socioeconomic status & 40 & Highly Encouraged \\
\hline Highest level of education & 37 & Highly Encouraged \\
\hline Ethnic origin & 43 & Highly Encouraged \\
\hline \multicolumn{3}{|l|}{ Interventions/Investigations } \\
\hline Timing of interventions & 55 & Mandatory \\
\hline $\begin{array}{l}\text { Results of investigations (e.g. } \\
\text { CK, ABG) }\end{array}$ & 35 & Highly Encouraged \\
\hline Equipment options & 42 & Highly Encouraged \\
\hline Functional related outcomes & 43 & Highly Encouraged \\
\hline \multicolumn{3}{|l|}{ Diagnosis } \\
\hline $\begin{array}{l}\text { Electrophysiology variables } \\
\text { (e.g. PSW) }\end{array}$ & 39 & Highly Encouraged \\
\hline \multicolumn{3}{|l|}{$\begin{array}{c}\text { Long Term Care/End of } \\
\text { Life }\end{array}$} \\
\hline Personal directives & 32 & Highly Encouraged \\
\hline Advanced care options & 39 & Highly Encouraged \\
\hline Long term care options & 36 & Highly Encouraged \\
\hline Palliative concerns & 37 & Highly Encouraged \\
\hline Spiritual concerns & 28 & Highly Encouraged \\
\hline
\end{tabular}


Table 6: Mandatory dataset items group discussion results

\begin{tabular}{|c|c|c|}
\hline GROUP & DATA FIELD & CLASSIFICATION \\
\hline \multirow[t]{25}{*}{ Demographics/Diagnosis/Genetics } & Consent Fields (CNDR) & Mandatory \\
\hline & Was consent signed on behalf of patient? (ALS) & Mandatory \\
\hline & Personal Info - Name, Contact Info, Gender, DOB, Status (CNDR) & Mandatory \\
\hline & Place of Birth, Location of Death (ALS) & Mandatory \\
\hline & Other registry participation? & Highly Encouraged \\
\hline & Live-in caregiver? & Mandatory \\
\hline & Highest education & Highly Encouraged \\
\hline & Gross household income & Highly Encouraged \\
\hline & Registered with local ALS chapter? & Highly Encouraged \\
\hline & Ethnicity & Highly Encouraged \\
\hline & Transportation availability & Highly Encouraged \\
\hline & Home care type and daily hours & Highly Encouraged \\
\hline & Availability of respite care & Highly Encouraged \\
\hline & Date of Exam, Clinic, Physician (CNDR) & Mandatory \\
\hline & Body Weight $(\mathrm{kg})$ \& Height $(\mathrm{cm})$ & Highly Encouraged \\
\hline & Revised El Escorial Criteria & Mandatory \\
\hline & Date of Symptom onset, Date of Diagnosis & Mandatory \\
\hline & Family history of ALS? & Mandatory \\
\hline & List affected relatives & Highly Encouraged \\
\hline & Family history of neurodegenerative disease? & Mandatory \\
\hline & Was a genetic test performed? & Mandatory \\
\hline & Type of test? Date and Lab Info & Mandatory \\
\hline & Was a mutation found? & Mandatory \\
\hline & Which genes were involved? & Highly Encouraged \\
\hline & Genetic mutation sequence variant (if available) & Highly Encouraged \\
\hline \multirow[t]{13}{*}{ Clinical Features } & Regions of involvement (first visit) & Mandatory \\
\hline & Region of symptom onset & Mandatory \\
\hline & Ongoing regions of involvement & Mandatory \\
\hline & Non-invasive ventilation & Mandatory \\
\hline & Tracheostomy & Mandatory \\
\hline & Feeding tube? & Mandatory \\
\hline & What is the patient's greatest symptom complaint? & Highly Encouraged \\
\hline & Does the individual display cognitive impairment? & Mandatory \\
\hline & Extent the cognitive impairment affects daily living? & Mandatory \\
\hline & Does the individual display behavioural impairment? & Highly Encouraged \\
\hline & What screening tests were used for assessment? & Highly Encouraged \\
\hline & Has patient been assessed by a behavioral neurologist or neuropsychologist? & Mandatory \\
\hline & Complete ALSFRS-R & Highly Encouraged \\
\hline \multirow{3}{*}{ Clinical Trials } & Clinical Trial Participation (and specify trial) (CNDR) & Mandatory \\
\hline & Last FVC \& Date & Mandatory \\
\hline & Riluzole Use \& Date & Mandatory \\
\hline
\end{tabular}

a registry of patients with ALS in Canada and the compatibility of such a registry within the CNDR network. The entire CALS membership including physicians, basic science and clinical researchers, ALS Clinic Directors, and allied health professionals were surveyed. The survey consisted of a webbased questionnaire developed and disseminated through SurveyGizmo (http://www2.surveygizmo.com/; Boulder, CO).

The survey asked respondents to describe their: 1. Expertise and affiliation; 2. Local multidisciplinary clinic characteristics if applicable; 3. Approximate number of new and followed ALS patients; 4. Interest or involvement in the CNDR; 5. Interest in participating in the CNDR as an ALS data collection site (ALS Clinic Directors only); 6. Projected benefits of an ALS registry for research and patients in Canada; 7. Projected drawbacks to an ALS registry for research and patients; 8. Desired rank for potential dataset item groupings based on importance to benefit their research and that of their collaborators.

In conjunction with the web-based survey, the CNDR also reviewed: 1 . The availability and timing of upcoming clinical trials in ALS; 2 . The epidemiologic needs for ALS in Canada; 3. Public health needs in Canada; 4. Availability of funding; 5. Availability of sufficient clinical and research expertise to form an ALS Disease Working Group as required by the CNDR organizational structure.

\section{Expected Case Ascertainment}

ALS clinic directors were asked to provide accurate estimates of the number of patients meeting at least El-Escorial criteria for clinically possible ALS in their clinic. Population statistics by province were obtained from the Canadian socioeconomic 
database from Statistics Canada (CANSIM) ${ }^{11}$. The at-risk population was considered age 25 years and above. The expected number of ALS cases was calculated based upon the previously reported Canadian point prevalence estimate of 6.07 per 100,000 within the Province of Alberta ${ }^{12}$. Expected maximum ascertainment was then calculated by dividing the ALS clinic patient estimates by the expected number of cases based on point prevalence.

Dataset Derivation Meeting. The participants met on April 28th and 29th, 2011 in Toronto, Ontario to derive the ALS dataset. Following introductory remarks, an update on the implementation of the CNDR across Canada, and a tour of the CNDR database, the group began with a facilitated discussion on what the priorities for the Canadian ALS Dataset should be in the context of the international ALS research community and a review of the results of the feasibility survey.

All CNDR datasets are constructed with a minimum dataset approach to help ensure complete, efficient, and accurate data collection within the clinic environment. Accordingly, CNDR dataset items fall within three categories. 1) The Mandatory category contains data items that must be captured at every clinic, and are surveyed nationally for quality control and completion; 2) The Highly Encouraged category contains data items that are of high interest in the research community but due to time and resource constraints may not be possible to collect at every site or clinic visit; 3) The Optional category contains data items that are collected at the specific desire of clinics individually or regionally. Every effort is made to collect all items where possible. The concept for the Mandatory, Highly Encouraged and Optional data categories were based on those from the Translational Research in Europe for the Assessment and Treatment of Neuromuscular Disease (TREAT-NMD) Network Global Registry Toolkit ${ }^{6}$.

In advance of the meeting, the meeting organizers ( $M$. Johnston, L. Korngut) utilized the scored rankings from the webbased feasibility survey dataset ranking to divide dataset item groupings into Mandatory or Highly Encouraged categories. During the survey respondents were also asked to indicate additional groupings they felt were important but were not included in the survey. At the beginning of the meeting on April 29, 2011, Nominal Group Technique (NGT) was employed by the organizers to score and rank these additional items/groupings from the feasibility survey. Nominal Group Technique is a consensus method with an extensive use in the fields of health and medicine. NGT is a "structured meeting" that defines a clear process to obtain consensus from a group of experts or other groups ${ }^{13}$. The data items/groupings with the top three scores were assigned within the Mandatory category with the remainder placed in the Highly Encouraged category. Following this effort, group consensus was obtained with respect to the classification of each data item. To facilitate efficient consensus-based discussion, participants were organized into small groups based on expertise (Demographics/Diagnostics/Genetics; Clinical Features; and Clinical Trials). Each group consisted of four members and was responsible for determining the data field inputs and parameters within each Mandatory category. Each group was required to achieve consensus on the individual items discussed and any items for which consensus could not be achieved were discussed with all of the participants in a larger
Table 7: Highly encouraged items group discussion results

\begin{tabular}{l|l}
\hline \multicolumn{1}{c}{ GROUP } & \multicolumn{1}{c}{ DATA FIELD } \\
\hline $\begin{array}{l}\text { Past Exposures/Possible } \\
\text { Risk Factors }\end{array}$ & Occupation \\
\cline { 2 - 2 } & Military Service \\
\cline { 2 - 2 } & Smoking history \\
\cline { 2 - 2 } & Trauma history \\
\hline Interventions/Medications & Secretion interventions used? List intervention type and date \\
\cline { 2 - 2 } & Airway interventions used? List intervention type and date \\
\cline { 2 - 2 } & Manual/power chair use? \\
\cline { 2 - 2 } & Orthotics use \\
\hline Associated Symptoms/ \\
Co-Morbidities
\end{tabular}

group session. If large group consensus could not be reached, then the NGT would be employed to re-rank the controversial items. The entire process was then repeated to achieve consensus on data items within the Highly Encouraged and Optional category.

Following the Dataset Derivation Meeting a draft data collection form was sent to the meeting attendees to ensure all data fields and parameters had been captured accurately. Subsequently, the final dataset was circulated a second time to all meeting participants, the CNDR Advisory Committee and the ALS Society of Canada for approval in accordance with CNDR procedure.

\section{RESULTS}

ALS Feasibility Survey. The ALS web questionnaire was sent to the entire CALS network that included 59 clinicians, researchers and allied health professionals. Twenty-four respondents completed the questionnaire (41\%). Respondents identified themselves as ALS clinic directors (37.5\%), basic scientists $(4.2 \%)$, clinicians $(29.17 \%)$, and clinical researchers (29.2\%). Eleven multidisciplinary ALS clinic directors completed the questionnaire. Seventy five percent of respondents indicated that their patients were seen in a dedicated ALS clinic.

Respondents ranked possible dataset item groupings according to perceived importance to their research and that of their collaborators. Table 1 lists the top nine groupings by average rank (low score $=$ high importance).

Sixteen professionals responded that they were interested in participating in the ALS Disease Working Group that would oversee the development and maintenance of the ALS dataset, 
provide peer review for data release inquiries, and provide oversight for scientific integrity of the ALS component of the CNDR. Sixteen experts responded with interest in participating in the Dataset Derivation meeting with some overlap with those demonstrating interest in the disease working group.

The feasibility web questionnaire identified sufficient interest from ALS clinicians and researchers in participating in the proposed registry to justify proceeding further. The feasibility survey findings were reviewed by representatives from CALS, the ALS Society of Canada and the CNDR. Considerations included upcoming and ongoing clinical trials and studies in ALS, gaps in understanding of the epidemiology of ALS in Canada and ability of the proposed registry to generate data to advocate for public health needs of the ALS population. It was unanimously agreed to proceed with the development of a Canadian ALS dataset.

Expected Case Ascertainment. Expected case ascertainment was calculated by province and was found to be higher than expected based on the available population-based point prevalence estimate. Calculations are summarized in Table 2.

ALS Dataset Development. In April 2011, twelve experts from neurology, physiatry and clinical genetics attended the Dataset Derivation meeting in Toronto, Ontario. In advance of the meeting, based on the average score from the feasibility webbased questionnaire the nine ranked data groupings (Table 3) were divided into Mandatory and Highly Encouraged items.

Meeting attendees were asked to score additional item groupings captured during the web-based feasibility questionnaire based on a relevance scoring matrix (Table 4). The aggregated scores were used to rank the item groupings with the top five being assigned to the Mandatory category for further discussion (Table 5).

Mandatory Items Discussion. For the items in the Mandatory category, three small groups each with four members were formed. Consensus was achieved on all data fields and parameters at the small group level. The final dataset items and parameters produced by each group appear in Table 6 .

Highly Encouraged Items Discussion. For the items in the Highly Encouraged category, four small groups each with three members were formed. Large group discussion about palliative care, cognitive abilities, and access to healthcare services occurred. The final dataset items and parameters produced appear in Table 7.

In total the dataset comprises 103 discrete fields, 49 of these are in the Mandatory category. Data will be collected at CNDR clinical sites employing both a physician data collection form (medical data) and a patient data collection form (mainly sociodemographic data) to increase efficiency with the larger dataset.

\section{Discussion}

The CNDR aims to facilitate clinical research into neuromuscular diseases in Canada. Data collected by patient registries is particularly useful as it is highly generalizable to the patient population studied. Patient registry findings are most generalizable when they are demonstrated to be populationbased. The initial aim of the ALS component of the CNDR is to demonstrate population-based level case ascertainment in multiple provinces and ultimately on a national level. To assess the feasibility of eventual complete or near complete ascertainment of ALS cases we calculated the expected maximum case ascertainment based upon ALS clinic estimates of number of cases compared to calculations of expected cases based on previously reported point prevalence demonstrated higher than expected ascertainment. The estimated actual number of ALS cases within ALS clinics participating in this study exceeded the expected cases derived from a populationbased point prevalence estimate. Despite the lack of clinics in certain regions (e.g. Northern Ontario, Prince Edward Island and Newfoundland) the overall number of actual ALS cases within the participating 14 clinics was $123 \%$ of the expected number of cases in Canada. The higher than expected number of actual cases further supports the usefulness of a national patient registry to delineate the epidemiology of ALS in Canada and assess discrepancies between the expected and actual burdens of ALS in Canada. There are possible explanations that must be considered including overestimation of existing ALS cases in ALS clinics but we feel that this is unlikely given the consistent use of clinical databases and visit scheduling software in determining actual case numbers for this study. We also feel it is unlikely that ALS patients are being seen regularly in multiple clinics based on referral patterns and communication between clinics for patients outside of specific clinic catchment areas. Future research on the epidemiology of ALS will be facilitated by this registry once implemented.

The derivation of the ALS dataset from feasibility study to finalized dataset took approximately eight months (November 2010 to July 2011). The dataset was derived both with strong investigator and clinician support and also a robust methodology to minimize bias. The inclusion of a breadth of professionals including clinicians, researchers and allied health professionals in the feasibility study resulted in broad dataset items that reflect the needs of the Canadian ALS clinical and research communities. The viability of each dataset item will be closely monitored by the CNDR ALS Disease Working Group upon initiation of data collection and the dataset will be accordingly revised to remove any items collected with insufficient frequency. Software design of the data collection module for the CNDR will begin in January 2012 and data collection will begin in CNDR clinics nationally in mid-2012. Building this long sought-after resource is a significant step forward for the Canadian ALS patient and research communities.

\section{ACKNOWLEDGEMENTS}

The development of the Canadian ALS Dataset was supported by the ALS Society of Canada (Toronto, Ontario). The CNDR was made possible through generous contributions made by the ALS Society of Canada, Families of SMA Canada (Chilliwack, British Columbia), Jesse's Journey (London, Ontario), and the Marigold Foundation (Calgary, Alberta). The authors would like to thank Dr. Craig Campbell (Western University, London, Ontario) for his contributions to this manuscript. 


\section{REFERENCES}

1. Johnston CA, Stanton BR, Turner MR, et al. Amyotrophic lateral sclerosis in an urban setting: a population based study of inner city London. J Neurol. 2006 ;253(12):1642-3.

2. Zinman L, Cudkowicz M. Emerging targets and treatments in amyotrophic lateral sclerosis. Lancet Neurol. 2011;10(5): 481-90.

3. Beghi E, Pupillo E, Zoccolella S, European Amyotrophic Lateral Sclerosis Consortium (EURALS). 148th ENMC international workshop on the scientific contributions of the EURALS consortium on amyotrophic lateral sclerosis. Neuromuscul Disord. 2009;19(5):379-81.

4. Sherman A, Bowser R, Grasso D, et al. Proposed BioRepository platform solution for the ALS research community. Amyotroph Lateral Scler. 2010;12(1):11-16.

5. Thompson R, Schoser B, Monckton DG, Blonsky K, Lochmüller H. Patient Registries and Trial Readiness in Myotonic Dystrophy-TREAT-NMD/Marigold International Workshop Report. Neuromuscul Disord. 2009;19(12):860.

6. Bushby K, Lynn S, Straub T, TREAT-NMD Network. Collaborating to bring new therapies to the patient--the TREAT-NMD model. Acta Myol. 2009 July;28(1):12-15.
7. Sárközy A, Bushby K, Béroud C, Lochmüller H. 157th ENMC International Workshop: patient registries for rare, inherited muscular disorders 25-27 January 2008 Naarden, The Netherlands. Neuromuscul Disord. 2008;18(12):997-1001.

8. Dreyer NA, Garner S. Registries for robust evidence. JAMA. 2009; 302(7):790-1.

9. Donaghy C, Clarke J, Patterson C, Kee F, Hardiman O, Patterson V. The epidemiology of motor neuron disease in Northern Ireland using capture-recapture methodology. Amyotroph Lateral Scler. 2010;11(4):374-8.

10. Byrne S, Walsh C, Lynch $C$, et al. Rate of familial amyotrophic lateral sclerosis: a systematic review and meta-analysis. J Neurol Neurosurg Psychiatry. 2011;82(6):623-7.

11. Canadian socioeconomic database from Statistics Canada (CANSIM) 2011[homepage on the internet]. Ottawa, Ontario: Statistics Canada. 2011 [cited 2011 July 1]. Available from: http://www5.statcan.gc.ca/cansim/home-accueil?lang=eng.

12. Wolfson C, Kilborn S, Oskoui M, Genge A. Incidence and prevalence of amyotrophic lateral sclerosis in Canada: a systematic review of the literature. Neuroepidemiology. 2009;33 (2):79-88.

13. Fink A, Kosecoff J, Chassin M, Brook RH. Consensus methods: characteristics and guidelines for use. Am J Public Health. 1984; 74:979-83. 